\title{
Perceptualism and the epistemology of normative reasons
}

\author{
Jean Moritz Müller ${ }^{1}$ \\ Received: 1 April 2020 / Accepted: 2 November 2020 / Published online: 17 November 2020 \\ (C) The Author(s) 2020
}

\begin{abstract}
According to much recent work in metaethics, we have a perceptual access to normative properties and relations. On a common approach, this access has a presentational character. Here, 'presentational' specifies a characteristic feature of the way aspects of the environment are apprehended in sensory experience. While many authors have argued that we enjoy presentations of value properties, thus far comparatively less effort has been invested into developing a presentational view of the apprehension of normative reasons. Since it appears that this view would offer much the same theoretical benefits as presentational views of the apprehension of value, it seems worthwhile redressing this imbalance. My paper aims at doing so, focusing on concern-dependent practical reasons. After clarifying the central commitment of this view, I assess a recent proposal by Dancy (Ethics 124(4):787-812, 2014) which provides a detailed characterization of the relevant type of cognition. I argue that Dancy ignores one of the central features of a presentational access to normative reasons and therefore misidentifies which actual psychological phenomena are apt to play this role. In this context, I also assess and reject further candidates that might seem fitting for this purpose. In the remainder of the paper, I then offer a more adequate account which specifies an actual form of presentational access to concern-dependent practical reasons and provide the contours of a more substantive account of its nature.
\end{abstract}

Keywords Epistemology of normative reasons · Concern-dependent reason · Perception $\cdot$ Presentation $\cdot$ Seeing-as $\cdot$ Affordance

\section{Introduction}

Much current work in metaethical epistemology is concerned with the possibility of a perceptual access to normative properties and relations (e.g. Chappell 2008; Oddie 2005; Audi 2014; Cowan 2015; Tappolet 2016; Milona 2017). This development is

\footnotetext{
$凶 \quad$ Jean Moritz Müller

jean.moritz.mueller@gmail.com

1 Institute of Philosophy, University of Bonn, Am Hof 1, 53113 Bonn, Germany
} 
motivated by several aims. One is to provide an account of how normative judgments might be non-inferentially justified. Such an account seems attractive, at least in part, since it purports to avoid familiar regress problems concerning their justification. Perceptual experiences non-inferentially justify corresponding empirical judgments without themselves standing in need of justification. Thus, if there is a perceptual form of access to the normative realm, this provides some ground for thinking that we can give an analogous treatment of normative judgment.

Some authors also wish to fend off a prominent epistemological concern with normative realism. If there are objective normative properties and relations, it can seem difficult to see how they might fit into the ontology of the natural world. Accordingly, they can also seem epistemologically problematic in that they require expanding the familiar repertoire of empirical ways of knowing so as to make room for a special faculty of intuition. However, if we can demystify the idea of a perceptual access to normativity, this should help defuse this epistemological concern.

One prominent way of approaching this task is to conceive of this access as sharing the characteristic phenomenological and intentional profile of ordinary sensory perceptions. According to this approach, perceptual access to normative properties and relations has a presentational character (e.g. Oddie 2005; Roberts 2013; Kauppinen 2013; Dancy 2014; Tappolet 2016; Poellner 2016). Here, 'presentational' specifies a characteristic feature of the way aspects of the environment are apprehended in sensory experience. From a first-person point of view, sensory experiences have the character of impressions or appearances. In having them, we are presented with material objects and their properties. By arguing in favour of a presentational form of access to the normative realm, proponents of this approach aim to take seriously the subject's perspective on ordinary perception and, in this respect, continue a prominent line of ethical intuitionism in the phenomenological literature (e.g. Meinong 1972; Scheler 1973). Relatedly, the approach is able to draw on a well-developed model of the epistemic import of perception. On this account, perceptual experience provides non-inferential justificatory or evidential support in virtue of its presentational character (e.g. Chudnoff 2013; Schellenberg 2013; Bengson 2015). This view purports to avoid regresses of justification on the basis of an attractively unified picture on which the phenomenology of perceptual experience and its normative role are tightly connected.

Thus far, this take on a perceptual access to normativity has been most prominently defended in the epistemology of value. Especially over the last decade, there has been a remarkable surge of interest in the idea that our most basic grasp of evaluative properties_-both thin (goodness, badness) and thick (e.g. injustice, dangerousness)—is presentational (e.g. Roberts 2013; Kauppinen 2013; Tappolet 2016; Poellner 2016). While perceptual accounts have attracted some attention also in neighboring domains of metaethical theorizing, it is yet notable that so far comparatively less attention been accorded to the idea of a presentational way of apprehending normative reasons. On a closer survey of the field, we find some views that are intended to be sufficiently general as to make room for perception-like forms of access to different normative properties and relations (e.g. Milona 2017). Moreover, there have also been a number of attempts to render plausible the claim that we enjoy perceptions specifically of normative reasons (e.g. Scanlon 1998, chapter 1; Schroeder 2007, chapter 8; Bedke 
2009, chapter 1; Milona and Schroeder 2019). That said, little effort has been invested into demystifying this claim by exploring and defending the idea that the property of being a normative reason qualifies as a possible object of presentation. Notwithstanding some important preliminary work by Dancy (2014), there is thus far no focused and sustained attempt to show that we enjoy presentational access to the property of favoring a specific action or attitude. ${ }^{1}$

To properly appreciate that we are here dealing with a distinct epistemological project, it is worth noting that while the domain of evaluative properties is taken by many to overlap with the domain of normative reasons, the latter is commonly seen as extending far beyond the former to include many non-axiological facts or states of affairs. Moreover, to apprehend an evaluative property that is plausibly also a normative reason (e.g. to grasp the injustice of some policy) is not the same as apprehending its character as favoring a certain conduct or attitude (e.g. disapproval or protest). In this respect, views committed to a presentational access to evaluative properties are not ipso facto committed to a presentational access to the property of being a normative reason. $^{2}$

It seems to me that the current epistemological imbalance between these two domains of metaethical inquiry is worth remedying for a number of reasons. To begin with, the putative benefits of the associated non-inferential model of the justification of empirical judgments should be much the same in connection with judgments about normative reasons as they are in connection with evaluative judgments. It would seem that the appeal to a unified picture of the phenomenology and the epistemic import of perceptual experience holds the same promise of stopping justificatory regresses in the former as it does in the latter.

A presentational view of the apprehension of normative reasons seems worth elaborating also in order to assess the merits of a perceptualist response to epistemological concerns about normative realism. Although these concerns have first explicitly been formulated for the case of values (Mackie 1977, 38f.), perceptual accounts in the epistemology of normative reasons can be seen as motivated by parallel epistemological worries. Generally, the property of being a normative reason for or favoring a certain response raises much the same metaethical concerns as values. Like evaluative

\footnotetext{
1 Though she does not explicitly speak of a presentational character of perception, Church (2013, chapter 3) might be considered a further exception. Her account is more restrictive than Dancy's, though, focusing entirely on the idea that perceptual experience has objective purport. This is only one aspect of its presentational character, though. Cf. Sect. 3.1. Also, Church says rather little about the apprehension of the distinctive normative force possessed by normative reasons in contrast to explanatory reasons or causes. The notion of a presentation of reasons is also touched on, but not elaborated, in Bedke (2009, p. 693). While Schroeder's (2007, chapter 8.4) account of desires as involving 'salience-strikings' may seem close to recognizing a presentational access to normative reasons, too, he does not get this notion into proper focus, though. Cf. p. ${ }^{8}$, n. 7. Also, salience-strikings are supposed to apprehend reasons in virtue of bearing systematic connections to them on the lines posited by common reductive-naturalist theories of content. Cf. also Milona and Schroeder (2019). It is not clear that these theories speak to the idea of presentation, though (e.g. Kriegel 2012; Mendelovici 2018, chapter 4).

${ }^{2}$ One might want to exempt theorists who give a reductive account of something's being valuable in terms of the higher-order property of having more basic properties that constitute normative reasons and who are also committed to a presentational access to value. But this combination seems rare. At any rate, to my knowledge there has thus far been no substantive account of what presentations of this complex higher-order property would be like.
} 
properties, it purports to be an objective, normative property, which can appear not to fit into the ontology of the natural world (e.g. Bedke 2010; Parfit 2011). Moreover, as several authors have recently argued, it actually makes no difference here whether we consider basic, non-derivative reasons or reasons grounded by an agent's ends or concerns (Bedke 2010; cf. also Shafer-Landau 2003, p. 211; Scanlon 2014, 16f., n. 1). Assuming the favoring-relation is metaphysically just as suspect as values, it seems that a corresponding need for special epistemological treatment arises also in the case of normative reasons. As a way of explicating the idea of normative perception that is phenomenologically sensitive and draws on a rich intuitionist tradition, an explicitly presentational understanding of this form of access thus seems worth exploring in this case, too.

Finally, a focused treatment specifically of normative reasons makes sense in this context also since it can accommodate for what is specific to reasons in comparison to other normative properties. In this respect, it has an advantage over perceptual approaches that are targeted towards a more general epistemology of the normative. ${ }^{3}$

In this paper, I make a detailed case for a presentational approach to the apprehension of normative reasons. I begin with an initial outline of the type of epistemic access that this approach is committed to (Sect. 2). I then consider in some more detail the sort of cognitive state that is supposed to constitute this access and whether any actual psychological phenomena might be identified as a state of this sort. For this purpose, I assess Dancy's recent proposal that we have access to normative reasons by means of what he calls practical seemings (Sect. 3). While Dancy's considerations help specify several important marks of presentations of normative reasons, I will argue that his account ignores one of their main features and, as a consequence, misidentifies which actual phenomena are apt to play this role. I here also discuss and reject further alternative candidates one might consider in this context. The central contribution of my paper is to offer a more adequate account which specifies an actual form of presentational access to reasons. Focusing on practical reasons that derive from an agent's concerns, I will show that there is a very plausible candidate for this access (Sects. 4 and 5) and provide the contours of a more substantive account of its nature (Sect. 6).

Although normative force that derives from an agent's concerns has not traditionally been the target of metaphysical or epistemological queerness objections, I here follow the increasingly prominent view that these objections are best construed as targeting any form of objective normativity. As is testified, for example, by disagreements about what reasons an agent actually has relative to her concerns, ascriptions of such reasons to an agent are about normative force in a recognizable objective sense (Bedke 2010, 48f.). I hence assume that concern-based reasons are no easier to integrate into a naturalistic worldview than forms of non-derivative normativity. ${ }^{4}$

\footnotetext{
3 In this connection, cf. also the recent discussion of different ways of fleshing out the 'guise of the normative'-view of desire in Milona and Schroeder (2019).

4 While, in this paper, I assume that there are practical reasons that derive from an agent's concerns, I take no stand on whether concern-based reasons exhaust the space of practical normative reasons.

Those who think that concern-based reasons are reducible to natural properties or facts and pose no epistemological queerness problem either may still be interested in the project of this paper inasmuch as it prepares the ground for a non-inferential view of the justification of reason judgments.
} 
While the ultimate goal of this project is to develop a thoroughgoing account of the epistemic significance of a perceptual access to reasons, I here follow a common procedure in metaethical epistemology in assuming that such an account is best provided after we have elucidated the nature of the relevant cognition and shown it to form part of the familiar repertoire of psychological phenomena (e.g. Audi 2014; Dancy 2014; Tappolet 2016). In this paper, my concern is with these latter tasks.

\section{Some initial clarifications}

The aim of this paper is to develop and defend the view that we have perceptual or perception-like epistemic access to normative reasons (for short: perceptualism). In line with a prominent explication of perceptual approaches in metaethical epistemology, I understand perceptualism to be committed to a type of cognition that is presentational. To convey a preliminary idea of the intentional profile characteristic of this type of cognition, it is helpful to contrast presentations with beliefs and judgments, which represent but do not present things as being some way. A good way to illustrate this difference is by means of the well-known Müller-Lyer illusion. In perceiving the two lines as being of unequal lengths, one has a certain visual impression: they are visually presented as having different lengths. In this respect, one's mental state differs from the state one is in when one merely believes that the two lines differ in length. This latter state does not constitute an impression of this difference. It represents, but does not present, the lines as unequally long.

I say more about presentation in the next section. By way of further initial clarification, it is important to note, though, that the idea of a presentational access need not be understood in terms of sensory experience. As many authors have argued, while sensory experience is a paradigm presentational state, there are also non-sensory presentations. For example, on a widely held view, we enjoy sentimental or affective presentations of value (e.g. Meinong 1972; Roberts 2013; Tappolet 2016). Others have proposed that what is traditionally known as rational intuition is not a kind of belief or judgment, but an intellectual presentation (Bengson 2015). As I understand perceptualism, the view is not committed to a sensory access to normative reasons. Indeed, there is an issue here as to whether normative properties can be possible objects of sensory experience in the first place. In line with parallel views in the epistemology of value, I will assume that perceptualism is committed only to the weaker claim that normative reasons are possible objects of presentation.

As I conceive of presentations of normative reasons, they present exemplifications of the relational property of being a normative reason to $\phi$ (where $\phi$ stands for an action or attitude). As indicated in the Introduction, the idea is not simply that they provide access to entities that exemplify this relational property. The view has it that its exemplification by some entity - the entity's character as a normative reason to $\phi$-is itself apprehended. ${ }^{5}$ What is presented is the very property of being a normative reason to $\phi$. In accordance with corresponding views in the epistemology of evaluative

\footnotetext{
5 I therefore do not count Tappolet (2016, chapter 5) as committed to a presentational access to practical normative reasons. Tappolet thinks of emotions as perceptions of certain value properties which are conceived as also constituting reasons for action. However, to think of emotions as perceptions of values which
} 
properties, I suppose that this is in fact compatible with the bearer of the property being itself merely represented.

In line with current orthodoxy, I understand the property of being a normative reason to $\phi$ as the property of speaking in favor of $\phi$ ing. Conceived this way normative reasons possess prescriptive force. For something to favor $\phi$ ing is for it to impose a certain claim on us to $\phi$. In the case of reasons that are based on our concerns, this claim derives, at least partly, from one or more of our desires, interests, likings or needs. For example, given that you desire to stay dry, that it is raining is a reason for you to take the umbrella. This state of affairs speaks in favor of your taking an umbrella in virtue of relating in a specific way, i.e. potentially frustrating, your desire to stay dry.

To say that a reason to $\phi$ imposes a claim on us to $\phi$ is not to say that, given this reason, we ought to $\phi$. After all, the overall balance of reasons may favor a different action or attitude. Nonetheless, where some state of affairs is a reason to $\phi$, we are wrong not to $\phi$ unless there is adequate countervailing justification. Normative reasons have deontic force in that justification is required to do other than what they favor doing.

In speaking of states of affairs as normative reasons, I am making a further assumption that needs stating explicitly. I shall suppose that the favoring-relation is exemplified by worldly entities, that is, non-psychological states of affairs. Intuitively, what counts in favor of taking an umbrella is the weather-that it is raining-not your belief about the weather. Similarly, when campaigning against an unjust policy, it is the policy—its being unjust—not your taking it to be so, that favors this action. As these examples suggest, states of affairs that constitute reasons may but need not involve aspects of our sensory environment. Importantly, as states of affairs, they are individuated in a more coarse-grained way than, and hence distinct from, propositions. The proposition that the approaching boar is dangerous and the truth-conditionally equivalent proposition that the approaching exemplar of sus scrofa is dangerous are not two distinct reasons to escape. There is only one state of affairs that favors escape. This view of the ontology of normative reasons is not unrivalled, but it enjoys a fair amount of support and adequately captures our common-sense view of what normative reasons are (Dancy 2014; Bittner 2001; Lowe 2008; Mantel 2015).

Given this conception of normative reasons, presentations of normative reasons are cognitive states that present deontic relational properties exemplified by states of affairs. We can think of such presentations as coming in two forms: a propositional form, which is correctly ascribed by sentences of the form 'It is presented to $S$ that $x$ is $F$ ', and a non-propositional or objectual form that is correctly ascribed by sentences of the form ' $x$ 's $F$-ness is presented to $S$ ' (where $F$ stands for the property of favoring a particular action or attitude). In this paper, I shall assume that both forms of presentation are suitable specifications of the perceptualist's target phenomenon. As for the cognitive state I will ultimately propose as a suitable candidate, opinions may perhaps diverge as to whether it is best conceived as an objectual or as a propositional form of presentation. However, on the assumption that both forms of presentation are apt for the perceptualist's purpose, I shall set this matter aside.

Footnote 5 continued

constitute reasons is not yet to conceive of them as apprehending these reasons as such, i.e. as favoring a certain conduct. 
With this outline of the relevant sort of cognition in place, let me now try and build a case in favor of perceptualism. In order to do so, it seems helpful to further explicate the notion of a presentation of normative reasons: what are the main general features of this type of cognition? Once we have clarified this, we can then look for actual psychological phenomena that exemplify these features.

I approach these tasks by considering Dancy's recent case in favor of perceptualism.

\section{Practical seemings}

\subsection{Dancy's proposal}

In recent work on moral intuition, Dancy (2014) introduces the notion of a practical seeming. A practical seeming is a non-sensory presentation of a state of affairs as favoring a certain conduct. Dancy develops a fairly detailed conception of practical seemings, which extensively draws on Bengson's (2015) pioneering account of presentation. As he goes on to argue, the emotions are a familiar aspect of our psychology that answers to this conception.

To get clearer on Dancy's proposal and make progress towards a more substantive view of presentations of normative reasons, it is helpful to first consider Bengson's view of presentation. Bengson offers a profile of general features of presentational states which is supposed to delineate them from nearby phenomena such as beliefs, judgments and imaginings. As he proposes, presentations are baseless, gradable, fundamentally non-voluntary, compelling and apt to rationalize assent from the subject's perspective. ${ }^{6}$ Let me go through these features in turn.

Presentations are baseless in that we do not form them. For example, a visual experience is a mental state that one simply has or fails to have. In contrast to a perceptual judgment, which is formed on the basis of a perceptual experience, the experience itself is a matter simply of being saddled with a particular impression. For presentations to be gradable is for them to vary along dimensions such as clarity or vividness. Presentations are fundamentally non-voluntary in that they are passive or receptive, i.e. ways of being acted on which are not within our conscious control. (I say more about the idea of non-voluntariness below.) And they are compelling in that we are typically disposed or inclined to assent to the respective appearance. Normally, this will also seem, at least on reflection, an appropriate thing to do. That is, when there are no countervailing reasons, it will seem rational to form a corresponding belief. In these latter two respects, presentations differ from imaginings. In imagining that there is a mug on the table, unlike in the case of visually perceiving this, one is neither

\footnotetext{
6 While Bengson's and Dancy's focus is on propositional presentations, I take it that the profile of features they attribute to them characterizes also their objectual form. Cf. also n. 8 .

In addition to the features noted in the main text, Bengson and Dancy also discuss translucency as a further characteristic of (a specific subclass of) presentations. I here set this aside since, as I view the debate, it is not a core characteristic of a perceptual access to normative properties. Cf. esp. Audi's (2014) view of value perception.
} 
inclined nor finds it appropriate to believe accordingly. Plausibly, this is because only when this state of affairs is visually presented one apprehends it as obtaining. ${ }^{7}$

As Dancy characterizes practical seemings, they conform to this profile, though with one modification. In this particular case, assent can be practical. Practical seemings are similar to desires in having motivational import. They compel their subject to act as the presented reason prescribes. We practically assent to this presentation by responding accordingly.

There is much to be said in favor both of Bengson's account of presentation as well as its adaption by Dancy for the purpose of clarifying the idea of a presentational access to normative reasons. Bengson helpfully identifies several features that speak to the character of sensory experiences as appearances while also pertaining to other states that are intuitively characterizable as appearances. In this way, he elucidates a fundamental respect in which these states resemble sensory experiences. Consider a familiar type of impression one has, for example, in detecting the invalidity of an inference. When an inference strikes one as invalid, as we might say, this is usually not a matter of forming an attitude on the basis of a prior conscious thought or experience. Rather, as the locution 'strike' suggests, some specific feature of the inference impresses itself on one in a way reminiscent of sensory experience. Like a visual experience, which may be more or less clear, this intellectual experience may vary in acuity. It may not be immediately transparent in which respect the inference is invalid. Also, there is a respect in which one is passive or acted upon in having this impression. Clearly, one does not decide to be struck by the inference's invalidity. Finally, in having this impression - as opposed to imagining the inference to be invalid—one seems to be in touch with an actual feature of it, which both inclines one to endorse the appearance and, ceteris paribus, also makes this seem a rational thing to do. ${ }^{8}$

\footnotetext{
7 It is a consequence of this that not every case of finding some consideration salient qualifies as presentation. For example, thoughts may occur to one in a way that is experientially immediate albeit without having the kind of objective purport characteristic of presentation. This distinction is emphasized by Church (2013, chapters 1.2 and 1.3), though it is frequently neglected. For example, Schroeder (2007, chapter 8.4) does not distinguish sufficiently clearly in this respect between salient considerations and presentations in characterizing salience-strikings.

One might think of adding further characteristics in connection with the objective purport of perceptual experience. According to Chudnoff (2013, pp. 18,37), presentations (which he conceives of as propositional) involve awareness of aspects of reality as making true their propositional content. This is a fairly substantial claim, though, which does not uncontroversially characterize ordinary sensory experience. In this connection, cf. Church's (2013, 31f.) criticism of Noë's (2003) conception of objective purport as involving two types of experiential content. Church's own conception similarly invites the charge of multiplying contents beyond what is attested by ordinary experience, though. This is because, on her view, objective purport requires actually imagining alternative perspectives on (or, in the case of relations, alternative arrangements of) what is perceived. Cf. Macarthur (2015).

8 My example moreover supports thinking of Bengson's profile of features as characteristic both of propositional and objectual presentation. Note that it can be construed both in propositional and non-propositional terms, that is, as a case of its being presented to you that the inference is invalid or as a case of your being presented with (struck by) its invalidity. As far as I can see, it does matter how we think of it in order to recognize is as conforming to this profile. The above characterization of the example seems apt for both cases.

Admittedly, some might maintain that we can assent only to propositional presentations. On closer inspection, however, this is not at all obvious (Textor 2007; Kriegel 2018, chapter 4). While I here lack the space to demonstrate this, this is neither true of what Dancy calls 'practical assent', i.e. compliance with practical reasons.
} 
To the extent that Dancy's conception of practical seemings builds on this account of presentation, it goes some way to substantiating the idea of a perception-like access to normative reasons. Also, I take it to be plausible in this context to suppose that in the case of presentations of practical reasons, assent can also be a matter of following practical inclinations. ${ }^{9}$ That said, insofar as-apart from this qualification-Dancy espouses Bengson's view more or less as it is his conception seems deficient in an important respect. This is because Bengson does not delineate the relevant class of phenomena sufficiently clearly. His treatment fails to make explicit an important difference between presentations and other forms of cognition. As will transpire shortly, paying heed to this difference is crucial in order to correctly identify actual psychological states that provide presentational access to reasons.

\subsection{Assessing Dancy's proposal}

The difference I have in mind is at least hinted at by Bengson when he characterizes presentations as fundamentally non-voluntary and contrasts them in this respect with doxastic attitudes. In explicating this feature of presentations in terms of passivity or receptivity, Bengson intends to capture the idea that "(...) one simply has (enjoys, suffers, hosts) such a state: it comes upon us unbidden, as if from without" (2015, p. 721). As I read him, he partly characterizes presentations as involuntary in the sense of not being subject to direct voluntary control: we cannot directly engender or get rid of them at will. In this respect, they contrast e.g. with choices, decisions and imaginings. But he also means to characterize presentations as being beyond the kind of indirect rational control we exercise over beliefs, e.g. by revisiting or resorting evidence, looking for new evidence etc., which gets more commonly classed as nonvoluntary. ${ }^{10}$ This relatively broad understanding of involuntariness is also supposed to help account for the fact that we are not responsible for presentations in the way we are for other cognitive states such as judgments and imaginings and that they are not governed by proprietary norms. Thus, according to Bengson, it is because perception is fundamentally involuntary that there are no perceptual norms analogous to the norms which apply to doxastic attitudes.

In contrasting the normativity of belief and perception, Bengson touches upon a crucial difference, albeit one that deserves more careful discussion and does not seem usefully treated under the rubric of (in)voluntariness. It is a salient dissimilarity between presentational states and doxastic attitudes that only the latter admit of normative reasons. This is attested by the fact that the question 'why do you perceive that $p$ ?' (and, similarly, in the case non-propositional forms of presentation: 'why do you perceive $x$ ?') cannot be sensibly read as a request for a justification. ${ }^{11}$ The same is true

\footnotetext{
9 In this connection, cf. also the characterization I offer of my proposed candidate for this access in Sect. 4.

10 I am not sure whether Bengson may be thinking of fundamental involuntariness as comprising even lack of a third type of control, which characterizes imagining, guessing, hypothesizing and judging. Cf. (2015, 721f.). If so, it is not clear, though, how he thinks of it as relating to direct voluntary and indirect rational control.

11 Bengson hints at this difference in a footnote, which suggests that insofar as presentations are fundamentally involuntary, they are not based on normative reasons. Cf. (2015, 730, n. 25). Yet this point bears further examination, which Bengson does not offer.
} 
of the questions 'why is it presented to you that $p$ ?' and 'why is $x$ presented to you?'. ${ }^{12}$ Similarly, presentations do not admit of motivating reasons, i.e. reasons for which we act or hold attitudes, either. It is also meaningless to ask 'why do you perceive that $p$ ?' or 'why is it presented to you that $p$ ?' (and, similarly, in the non-propositional case: 'why do you perceive $x$ ?', 'why is $x$ presented to you?') in order to enquire about reasons for which someone enjoys a presentational state regardless of their justificatory import. ${ }^{13}$ Although we may enquire about the causes of a presentation, it makes no sense to suppose that we are presented with objects or their qualities in view of or in light of something. Again, there is a difference here with belief: it is possible by asking 'why do you believe that $p$ ?' to enquire about the considerations in light of which someone believes that $p$.

In order to avoid a possible misunderstanding, it is important to be precise about the phenomena under consideration. It can perhaps seem that, depending on the examples we choose, there are cases of presentation which do admit of normative or motivating reasons. ${ }^{14}$ Consider common uses of 'perceive $x$ as $F$ '. For example, one might think of confronting a police officer who escalates a situation: 'why are you perceiving his behavior as demanding this violent response?' In this case, we are clearly asking for a justification. That is, we are enquiring about the reasons for which the officer sees the behavior in this way with a view to assessing whether they are reasons to see it in this way. However, it would be wrong to suppose that we are here dealing with a presentation that admits of reasons (cf. Müller 2019, 77f.). This is because the verbs 'perceive $x$ as $F$ ', 'see $x$ as $F$ ' etc. are ambiguous. We can use them both to ascribe an act of construing $x$ as $F$ as well as the corresponding construal, the impression of $F$-ness which one obtains in construing $x$ as $F$. Thus, we may ask someone to perceive or see something (e.g. an ambiguous figure, a certain behavior) in some way. In this case, we are asking her to perform the act of construing it in that way. Here, we are not requesting her to be presented with some property of it. This distinction matters for the interpretation of corresponding 'why'-questions. When we ask 'why are you seeing this behavior as demanding a violent response?' in order to enquire about the other's reasons for seeing the behavior in this way, the reason requested is her reason for construing it in some way, not for the corresponding impression or presentation. Asking for someone's reasons for having an impression of a certain normative property makes no more sense than enquiring about her reasons for having an impression of a certain shape or color. ${ }^{15}$

\footnotetext{
12 Since 'present' may seem to be a semi-technical term, one might think that it is not suitable for testing linguistic intuitions in this way. However, I think that in this case philosophical usage closely mirrors common usage. Cf. e.g. use of the term in the sentence:

Upon opening his eyes, he was presented with two hazy shapes.

A vast landscape clearly and vividly presented itself to her gaze.

13 While several authors have observed that perceptions do not admit of normative reasons (e.g. Brady 2011; Deonna and Teroni 2012, chapter 6), the parallel point about motivating reasons is rarely made explicit. Cf. Dietz (2018) and Müller (2019, chapter 3), though.

14 I thank an anonymous referee for raising this worry and for the following example.

15 Accordingly, it also does not make any difference with respect to the admission of reasons whether perceptions or presentations are of complex or higher-level properties or of basic sensory properties. I have also made this point in response to Poellner (2016) in Müller (2019, 65, n. 19).
} 
To further strengthen this view of presentations and reasons, it is worth noting that it is supported also by reflections on other locutions we use to ascribe motivating reasons for actions or attitudes. This should make it clear that the point ultimately supports an important, though little noted, distinction between different forms of intentionality. Consider an alternative way of attributing motivating reasons by using the verbs 'response' and 'meet'. Here, these terms are used in the same way that they are used e.g. when saying of someone that she responded to or met some event or state of affairs by acting in some way. For example, in saying that Sam responded to his opponent's move by moving his pawn (or, alternatively, that Sam met his opponent's move by moving his pawn) we are specifying the opponent's move to be a reason for which Sam moved his pawn (Bittner 2001, chapter 4; Müller 2019, chapter 3). This use of 'respond' and 'meet' is applicable to doxastic attitudes, but not to presentations. In particular, these verbs plausibly characterizing the very relation between a belief and its content. Thus, it is not unusual to say of some statement or proposition that it was met or responded to with belief or disbelief. ${ }^{16}$ Moreover, believing is, fundamentally, assenting to a proposition or acknowledging it as true. To acknowledge a proposition as true is to respond to its (apparent) truth in a particular way, i.e. in that way which is appropriate to true propositions. ${ }^{17}$ In contrast, we cannot respond to or meet something by being presented with it or by having a certain impression. In this respect, doxastic attitudes and presentational states are different kinds of intentional state.

This contrast in terms of responsiveness bears highlighting since it helps situate presentations more clearly within the familiar repertoire of psychological states. In particular, while amplifying the distinction stressed by Bengson between beliefs and presentational states, it helps clarify their relation also to other, non-doxastic attitudes. Thus, emotions admit of motivating and normative reasons, too. We commonly enquire about the reasons for which people are indignant, afraid, delighted etc. and assess whether they are reasons to be indignant, afraid, delighted etc. Moreover, as is seldomly noted, emotions likewise are intentionally directed at something insofar as they are responses. For you to be indignant about $x$ is for you to be indignant in light of or in response to $x$ (or, alternatively, to meet $x$ with indignation). Similarly, for you to be afraid of $x$ is for you be afraid in light of or in response to $x$ (or, alternatively, to meet $x$ with fear) (Norrick 1978, 65ff.; cf. also Müller 2017, 2019, chapter 3). ${ }^{18}$ Accordingly, emotions, too, seem to differ from presentations in respect of their intentionality (cf. also Peacocke 2004, 259f.; Müller 2019, chapter 3).

This further observation is significant in part in that it suggests that Bengson's account of presentations is incomplete in an important respect. It calls for further amendment since this difference between presentations and emotions is even less plausibly subsumed under the rubric of (in)voluntariness. Not only is there a clear respect in

\footnotetext{
16 Cf. e.g. the use of these verbs in the following sentences:

If she had told the police her reason for killing him, would she have been met with belief?

If they disclose, they will be responded to with belief and support.

17 I have elaborated this notion of acknowledgment in Müller (2017).

18 As these examples suggest, this point is not restricted to sophisticated emotions (like indignation), but applies also to basic ones which can take the form of more primitive quick-fire responses (like fear). As I have noted elsewhere (Müller 2019, 62), any case of fear of something is a response to something in the here relevant sense.
} 
which, at least typically, we cannot have or get rid of an emotion at will. Emotions are also quite often beyond the kind of indirect rational control we have over beliefs. Crucially, they are characteristically insensitive to relevant evidence (e.g. Goldie 2004). ${ }^{19}$ Thus, emotions seem to be on a par with presentations in being exempt from the forms of control Bengson refers to in explicating the idea of fundamental (in)voluntariness. This suggests that the contrast between responsive and non-responsive phenomena is more adequately treated as a contrast in its own right. ${ }^{20}$

Moreover, and perhaps most importantly, the responsive character of emotion spells bad news for Dancy's case for the existence of practical seemings. If emotions, but not presentations, are responses, they constitute a very different kind of intentional state. In this respect, there is a fundamental difference with presentations whose object or content does not provide a corresponding motivating reason. I take this to cast serious doubt on the view that emotions are practical seemings. Given their responsive character, they are the wrong kind of state to be of service to the perceptualist (cf. also Peacocke 2004, 259f.; Müller 2019, chapter 3).

To appreciate the force of this objection, it is helpful to emphasize that it goes beyond the observation that emotions, but not presentations admit of reasons, in relating this difference to the intentionality of each type of state. Presentational states and emotions fundamentally differ qua intentional. In Searle's (1983) terminology, they exemplify different kinds of intentional mode. Although it seems to me that the difference in respect of the admissibility of reasons by itself casts some doubt on Dancy's proposal, linking this point to the notion of intentionality makes it difficult to simply dismiss it as irrelevant to the nature of these two types of state. This is because their intentional profile is widely seen to be an essential feature of them. ${ }^{21}$ Let me clarify also that this objection does not boil down to the observation that emotions, but not ordinary perceptions, depend for their intentionality on other cognitive states (known as their 'cognitive base'; cf. Deonna and Teroni 2012). As many authors have noted, in order to be indignant about or afraid of some object or event, one must have some prior awareness of it. In contrast, this is not true of perceptual experiences, which seem to be 'self-standing' intentional phenomena. Although this is an important difference, too, it is relevant for my purposes only insofar as it underlines the idea that emotions are directed in a specific way that involves their responsive character. Indeed, a very simple and plausible explanation of the fact that emotions, but not perceptions, have

\footnotetext{
19 I take it that the same goes for any putative further kind of control we may have over imagining, guessing, hypothesizing and judging. At any rate, we are not free what, when and how we emotionally feel in the way in which we are free when, what and how we imagine, guess or hypothesize.

20 This is not to deny that it is importantly related to the difference in respect of indirect rational control (see main text below). In line with Bengson's view, there is, arguably, also a clear respect in which presentations, but not emotions, are receptive. However, while Bengson explicates the idea of fundamental involuntariness in terms of receptivity, he does not clearly distinguish receptivity from other forms of passivity (such as lack of direct voluntary control and lack of indirect rational control).

21 For example, Tappolet $(2016,39 f$.) argues that the difference between emotions and perceptions in respect of normative reasons is an artefact of the specific dependence of the values which she takes emotions to apprehend on certain natural properties. According to her, this difference does not tell us anything about the nature of emotion that might undermine a substantive analogy with perception. Whatever one might make of this reply, it is no longer available once we recognize the link between the directedness of emotions and motivating reasons.
} 
a cognitive basis is precisely that only in the former case, the intentional content of the state is also a motivating reason (Hildebrand 1969, 13ff.; Müller 2019, 68f.). This requirement is an instance of the common constraint that motivating reasons for an action or attitude must be within the agent's cognitive ken. The main dialectical force of this difference, I thus take it, is that it speaks to the specific way in which emotions are intentional and which distinguishes them from presentations. ${ }^{22}$ It is this disanalogy which most clearly tells against Dancy's proposal.

Let me sum up then: While Dancy makes some progress towards elucidating the perceptualist's target phenomenon, he draws on a general account of presentation that does not properly distinguish presentations from other forms of intentionality. In turn, Dancy fails to specify a familiar psychological phenomenon that is apt to provide presentational access to reasons.

It is fair adding that Dancy is by no means alone in mistaking emotion for a kind of presentation. Many theorists sympathetic to the view that we enjoy presentational access to value think of this access as constituted by emotions (e.g. Roberts 2013; Kauppinen 2013; Tappolet 2016; Poellner 2016). Thus, if the considerations I have canvassed here are on the right lines, they tell against this group of views, too (cf. also Mulligan 2007; Dietz 2018; Müller 2019, chapter 3). Moreover, mutatis mutandis they rule out further candidates for a presentational access to normative reasons. In particular, they also tell against conceiving of this access in conative rather than emotional terms.

In line with a specific interpretation of the view that we desire something under a certain normative guise, one might suggest that we can instead conceive of desires as affording this access. ${ }^{23}$ However, what goes for beliefs and emotions, goes for desires, too. Desires admit of normative and motivating reasons and are directed in the same responsive way as beliefs and emotions. 'Why do you desire that $p$ ?' and 'why do you desire to $\phi$ ?' are most naturally construed as requests for reasons. Moreover, the verbs 'meet' and 'respond' apply also to the relation between a desire and its intentional content. For you to desire that $p$ (to $\phi$ ) is for you to respond to the prospect that $p$ (of your $\phi$ ing) (or, alternatively, for this prospect to be met by you) with desire. It is in light of this prospect or, most plausibly, its character as an end that you hold this attitude. Note, further, that this account sits well with the fact that desires, too, have

\footnotetext{
22 As far as I know, this has so far not been properly appreciated by friends of perceptual accounts of emotion. While Tappolet (2016, p. 30) supposes that this dissimilarity is compatible with emotions being presentations, she takes no account of the fact that the cognitive base of an emotion is an enabling condition for it to be directed as a response to something. Poellner $(2016,275 \mathrm{ff}$.) questions the disanalogy by arguing that perceptions of higher-level properties (which he takes to include normative properties) are likewise dependent on cognitions of the subtending lower-level properties. A similar line is taken by Roberts (2013, 69) who focuses on aspectual presentation (cf. also Sect. 6). However, if cognitions are required in these cases, they differ from the cognitive bases of emotions in that they do not provide access to a motivating reason and hence do not serve as enabling conditions for those perceptions to be directed in the way emotions are. This point is also absent from Milona and Naar's (2020) otherwise very sensitive discussion of cognitive bases.

23 Though his official view is that desires are presentations of value, Oddie's claim that desires present their object as "needing to be pursued, or promoted, or embraced" $(2005,41)$ might be read as pointing into this direction. For arguments for a 'guise of reasons'-view of desire in terms of perceptions of reasons, cf. Milona and Schroeder (2019). Cf. also Scanlon (1998, chapter 1), Schroeder (2007, chapter 8.4), Bedke (2009, p. 693).
} 
a cognitive basis. In order for you to desire that $p$ (to $\phi$ ), this prospect must in one or another way be on your mind (e.g. Brentano 1995, 60f.; Mulligan 2007). As in the case of emotion, we can give a straightforward explanation of this requirement by adverting to the responsive character of desire. ${ }^{24}$

In order to build a more adequate case for perceptualism, I shall thus explicitly add the non-responsive character of presentations to the profile of general features of presentational states. More specifically, I propose to distinguish between lack of direct voluntary control, lack of indirect rational control and non-responsiveness as different general features of presentations. As I think of the latter two features, they are closely related, though. As normally conceived, indirect rational control is exercised over attitudes qua responses. We exercise rational control over beliefs by forming and revising them in response to adequate evidence. While this type of control is thus applicable only to responses, the case of the emotions at the same time casts some doubt on whether all responses are subject to it. ${ }^{25}$

I take this to be a non-trivial amendment of Bengson's account of presentations and, accordingly, of Dancy's characterization of the perceptualist's target. Whilst acknowledging the specificity Dancy highlights in respect of practical assent, I will assume in what follows that presentations of practical reasons are characterized by a more complex profile of features than Dancy recognizes and which rules out emotions and any other responses as possible candidates for this target. With this amended account in place, let me, then, introduce a more promising contender.

\section{Presentations of affordances}

There has been considerable interest in the idea that we enjoy perceptual access to normative properties also in philosophical and psychological research on perception.

\footnotetext{
${ }^{24}$ One might maintain that my case against presentational views of emotion and desire does not rule out that they involve presentations of reasons in addition to being responses. As I understand this proposal, it conceives of emotions (desires) as having parts or constituents besides the intentional mode we ascribe by means of the canonical locutions 'fear of $x$ ', 'indignation about $x$ ' ('desire that $p$ ', 'desire to $\phi$ ') etc. After all, as I argued, the modes thus ascribed are not instances of presentation. Insofar as the view's commitments outrun what these locutions purportedly pick out, it requires some special motivation, though. This is also since its rival can accommodate for some of the core intuitions that motivate presentational views of these states. For example, if desires are responses to prospects qua ends, then, on a common understanding of ends, they presuppose apprehension of those prospects as something to be pursued or promoted. This is because as reasons for which one has a desire, their character as ends must be on our mind. And it does not seem implausible that this prior grasp need not be doxastic, but may be presentational. (Certainly, one can desire that $p$ without believing that $p$ is to be pursued.) On this view, when we desire some prospect, there will often be a presentation of it as to be pursued or promoted. Note, though, that as a state that provides access to a motivating reason for the desire, this presentation is not a part of it, but an entirely distinct state. Cf. Müller $(2019,74 f$.). Accordingly, there is then still a substantive question as to its nature. Cf. also Deonna and Teroni (2012, 93f.), Müller (2019, p. 118), Mitchell (2019) on views of emotion as founded on non-doxastic forms of value apprehension.

25 This amendment of Bengson's profile seems to me to have ramifications for those further aspects of presentations he means to elucidate in terms of fundamental (in)voluntariness. Once we distinguish between non-responsiveness, direct voluntary and indirect rational control, it becomes plausible to suppose that our lack of responsibility for presentations as well as the absence of proprietary norms is due the first, rather than second or third, of these features. However, I here lack the space to show this.
} 
The phenomena in the focus of this debate are usually not explicitly characterized as presentations of normative properties. Instead, they are described as experiences of a specific type of affordance.

The notion of an affordance is commonly associated with J. J. Gibson's ecological psychology (esp. Gibson 1979). As Gibson uses the term, it picks out a specific type of relational property that is exemplified in a creature's environment. Affordances are opportunities for bodily action furnished by one's perceptible surroundings. For example, a cup filled with water has the property of being 'drinkable from'; a chair has the property of being 'sittable-on'. Importantly, these properties are relative to specific individuals. A full cup affords drinking from only for a creature with the ability to drink. ${ }^{26}$ Moreover, affordances are perceptible. Here, the guiding idea is that we normally do not infer what an object affords on the basis of a prior grasp of its other properties, but are experientially sensitive to its affordances. In looking at a chair, we do not infer that it affords sitting on from a prior impression of its shape, size and constitution. Rather, this relational property is an aspect of how the chair presents itself in looking at it.

The Gibsonian understanding of affordances as perceivable action opportunities has long been dominant. However, affordances are also often conceived in directive terms. Proponents of this further conception maintain that we not only experience action opportunities, but also solicitations for action. On this view, our surroundings also afford actions insofar as they perceivably invite or demand them.

The directive conception of affordances was prominent in Gestalt psychology (esp. Koffka 1935) and is enjoying increasing popularity also among contemporary philosophers (e.g. Kelly 2005; Dreyfus and Kelly 2007; Dokic 2010; Kauppinen 2018). ${ }^{27}$ As is widely agreed, directive affordances derive from an individual's concerns. It is because you have certain desires, interests or needs that those aspects of the environment which bear on these attitudes solicit a particular conduct (e.g. Koffka 1935, 353ff.; Dreyfus and Kelly 2007, p. 53; Rietveld and Kiverstein 2014, p. 341). In this respect, they differ from Gibsonian affordances. While all affordances are relative to an agent's abilities, directive affordances moreover depend on her motivational set.

I would like to propose that the type of experience that motivates the directive conception of affordances provides an alternative, more suitable candidate for presentations of normative reasons. More specifically, I have in mind experiences of a specific type of directive affordance whose soliciting modality is prescriptive. These are experiences of the environment as demanding or mandating action. I shall call them experiences of prescriptive affordances.

For this proposal to be plausible, it is, of course, crucial to show both that these experiences are a genuine aspect of our psychology and that they qualify as a presen-

\footnotetext{
26 According to Rietveld and Kiverstein (2014, 335ff.), affordances are determined by the abilities shared by communities or 'forms of life', rather than those of individuals. However, it occasionally sounds as though their main concern is to avoid conceiving affordances as contingent upon an individual's actual engagement with them. This aim is consistent with recognition of affordances as dependent on an individual's possession of certain abilities (as opposed to her exercise of them).

27 Cf. also Rietveld and Kiverstein (2014, 341f.), who generally conceive of affordances as possibilities for action, but maintain that some affordances in addition solicit action. Similarly, Siegel (2014) conceives of affordances as possibilities for action, but she delimits a specific class of affordances, which are experienced as soliciting a certain conduct. Cf. also Shepherd (2016).
} 
tation of the relevant sort. At first sight, it may perhaps seem that invoking experiences of prescriptive affordances amounts to a similarly obscure expansion of the familiar repertoire of psychological phenomena as the outright appeal to a special faculty of intuition. Let me thus try and show that this impression is unfounded.

One important reason for thinking that experiences of prescriptive affordances form part of our psychology is phenomenological. It is a familiar part of ordinary experience that our perceptible surroundings demand action from us. Consider some examples:

Close Talker. A colleague is talking to you. She is intruding your peripersonal space. You sense her proximity and feel pushed away. The close talker strikes you as to be backed away from.

Cake. The person at the neighboring table is having a piece of cheesecake for dessert. You have finished your meal and are no longer hungry. Still, the cheesecake appeals to you. It strikes you as something to try.

Beat. You are in a meeting, quietly attending a presentation. Somewhere outside a lighthearted pop song is playing. You are drawn in by the allure of the beat and compelled to tap along. You experience the beat as to be tapped along to.

To the extent that these examples resonate with everyday experience, it seems that we frequently enjoy impressions of being compelled or mandated to act by aspects of our surroundings. Further reflection on these cases moreover suggests that the experienced demand derives from a specific concern. Considering Close Talker, we can plausibly characterize your experience in terms of a certain felt tension. To appreciate this, imagine that you resist the pull to back away and try to keep your discomfort at bay. In this case, the talker's proximity likely 'asserts itself' as mandating a certain response. When this happens, it does not feel as though a claim is imposed on you by some external authority (as when receiving an order from someone else). Rather, the solicitation owes its authority to yourself: you feel answerable to this call in virtue of your concern to keep a comfortable distance. Similarly, the way the dessert appeals to you in Cake has its source in your culinary taste. It appeals to you as someone with a soft spot for this sort of cake. Again, first-personally, this is not like receiving an external directive, but a case of being compelled by your own likings. (The same goes for Beat. Here, the experienced demand to tap along has its source in your musical or, more specifically, rhythmic taste.)

To forestall a possible misconception, it is worth adding a qualification to this phenomenological account. Although the demands apprehended in these experiences derive from concerns, which frequently take the form of desires, the experiences themselves are phenomenologically different from the latter. In the foregoing section, I argued that desires and presentations exemplify different forms of intentionality. This difference is borne out also by first-person considerations contrasting desires with the experiences in the above examples. In the latter cases, a deontic property that is exemplified by some aspect of your circumstances impresses itself on you. In experiencing your colleague as to be backed away from or the music as to be tapped along to, your role is that of a recipient to how your surroundings appear to you. Things are quite different in the case of the corresponding desires. To suppose that in desiring to back away from the talker or dance along to the music you are merely receptive, too, is to mischaracterize the phenomenological profile of your 
desire. This account ignores that in having this desire you respond to the close talker (the music); it is your 'answer' to what you perceive. Relatedly, we can describe yourself as filled by this desire, while the parallel claim does not ring true of your deontic impression. ${ }^{28}$ Connected to this, it also does not seem plausible to suppose that such impressions are always associated with a corresponding desire to perform the respective action. Though perhaps natural, this supposition seems not to square with a related account of the phenomenology of non-deliberative action. Expanding on Beat, suppose that you automatically, unreflectively tap along to the perceived beat. In this type of case, it seems that the beat's allure draws action from you immediately. Here, the only phenomenology of a response is that of action. In performing what the music compels us to do, there is no interposition of a corresponding desire or other conative state between the call to tap along and your actual tapping. Rather, we simply find ourselves acting in response to the situation (Dreyfus and Kelly 2007, p. 52; cf. also Rietveld 2008, p. 992). Insofar as we wish to remain accurate to the agential phenomenology in such cases, we thus have some grounds to deny that experiences of ascriptive affordances need be accompanied by a corresponding desire.

In addition to first-person observations in support of experiences of prescriptive affordances, there are, moreover, explanatory considerations which attest to their having theoretical import, too. An important explanatory application of the idea that we experience prescriptive affordances concerns the normativity of non-deliberative action. This idea seems to make good sense of the fact that many of the actions we perform are apt for normative assessment despite being unreflective. There is a clear respect in which stepping away from the close talker is (pro tanto) appropriate even though you act without giving any thought to the matter (Dreyfus and Kelly 2007, 52f.). The claim that you thereby give into an experienced demand that derives from your concern to keep a comfortable distance makes this normative feature of your action intelligible. If maintaining this distance is an actual concern of yours, there is a respect in which you not only feel but actually are answerable to this demand (cf. also Helm 2001, chapter 3.3; Müller 2019, p. 80). There is some normative pressure to restore the way things ought to be relative to this concern. This makes it appropriate for you to act accordingly. ${ }^{29}$ (As should become apparent in the next section, the appropriateness of your action can ultimately be cashed out in terms of responsiveness to a normative reason.) While the normativity of automatic action is the main explanatory application of experiences of prescriptive affordances, it is worth noting that they have been accorded explanatory significance also in other domains, such as the acquisition

\footnotetext{
28 These points are ignored by those who suppose that conative phenomenology is presentational (e.g. Oddie 2005, p. 41). They loom large in certain places in the phenomenological literature. Cf. esp. Hildebrand (1969, $13 \mathrm{ff})$.

29 In this connection, cf. also Rietveld (2008), Brownstein and Madva (2012). These authors conceive of the adequacy of automatic action as a matter of successfully reducing a felt deviation from a certain norm. As Dreyfus and Kelly (2007) propose, this felt tension is a way of registering a prescriptive affordance. As far as I can see, Rietveld's (2008) view is congenial to this picture. While Brownstein and Madva do not explicitly appeal to affordances, their account of the normativity of non-deliberative action is similar, too, in that it invokes what Gendler (2008) calls 'aliefs' with imperative content. Siegel (2014, p. 64) gives a somewhat different account, which invokes affordances but does not explicitly attribute any role to concerns.
} 
of skill or expertise (esp. Rietveld 2008), ${ }^{30}$ the sense of joint agency (Dokic 2010) and the experience of trying (Shepherd 2016).

A question that might arise here is whether the phenomenological and explanatory considerations I have adduced actually support the claim that we are sensorily sensitive to demands for action or whether they are compatible with the view that such demands are non-sensorily presented even though they pertain to sensorily experienced objects. However, since perceptualism is not committed to sensory presentations of normative reasons, we can set this issue aside. To be fair, which stand one takes here may have ramifications for how to formulate my proposal. If the condition that affordances are perceptible is understood in terms of sensory perception and we suppose that these considerations do not support any form of prescriptive sensory experience, then they do not help much by way of establishing that we experience prescriptive affordances. I will here adopt a liberal understanding of the perceptibility condition, though, on which affordances are possible objects of presentation (sensory or non-sensory). This interpretation respects what I take to be the main intuitive consideration motivating this constraint. Those who opt for a stronger reading can simply drop the term 'prescriptive affordance' and reformulate my proposal in terms of experiences of concern-dependent demands.

With this terminological caveat in place, I shall take my above remarks concerning phenomenology and explanatory import to provide at least a preliminary case for the cognitive state I propose as an alternative for our target phenomenon. At any rate, what I have said so far suggests that the claim that we experience prescriptive affordances is both pre-theoretically warranted and has some theoretical credentials, too. I will give additional reasons to think that they constitute a non-mysterious aspect of our psychology in Sect. 6, where I offer a more substantive account which makes them intelligible as part of a larger, familiar class of experiences. Prior to this, however, I would like show that this further ontological inquiry is actually worthwhile by making it clear that they answer to our conception of the perceptualist's target phenomenon.

Some further reflection suggests that experiences of prescriptive affordances answer to this conception insofar as they satisfy the amended profile of general features of presentational states. For starters, they are baseless. As noted above, the experience of the close talker as to be backed away from is not the upshot of an inference or of taking at face value the content of a prior impression or thought. Instead, you are saddled with a particular impression of your colleague as calling for a particular conduct. What is more, this impression may come in different degrees of acuity. To see this, imagine varying the distance between you and your colleague. The closer she stands, the more conspicuous the experienced demand to back away. Experiences of prescriptive affordances are also beyond direct voluntary control. We can neither come to have nor stop having them at will. Moreover, they are not responses. It makes just as little sense to request motivating reasons or justifications for experiences of affordances than it does in the case of ordinary perception. In line with my earlier observations on such requests, the question 'why are you presented with/do you perceive a demand to $\phi$ ?'

\footnotetext{
${ }^{30}$ Although Rietveld is not concerned specifically with prescriptive affordances, he is plausibly read as ascribing to them a distinguished role. The solicitations registered through the kind of felt normative tension that is central to his view of expert action seem best conceived as prescriptive. On the theoretical role of soliciting affordances cf. also Rietveld and Kiverstein (2014).
} 
cannot be meaningfully construed as a request of either sort. ${ }^{31}$ A fortiori, they are not subject to indirect rational control either.

Considering the examples I have given, experiences of prescriptive affordances can also be recognized as compelling. To begin with, they are compelling in the same way as mundane sensory experiences. Compare your impression of the close talker as demanding backing away with merely imagining finding yourself in this situation. There is a difference here in terms of whether it seems to you that what you apprehend is an actual feature of your colleague. Moreover, when, in the former case, she strikes you as demanding more distance, the objective purport of your experience also inclines you to take the impression as face value and, other things being equal, makes it seem rational to do so. Perhaps more saliently, though, in experiencing the close talker as to be backed away from, there is also a definite inclination to move backwards. ${ }^{32}$ In following this inclination, you comply with the experienced demand and, in Dancy's terms, practically assent to the way you colleague appears. Assuming you have no reason to distrust your impression, this again seems, on reflection, rational to do. This is because, in experiencing your colleague as too close, you sense a deviation from how things should be relative to your concern. In sensing this deviation, you feel answerable to the affordance so that acting accordingly seems (pro tanto) appropriate.

It appears, then, that experiences of prescriptive affordances fit the perceptualist's target in that they exhibit the general features of presentations specified in the foregoing section. Moreover, insofar as they are not responses they clearly provide a more suitable candidate than emotions or desires. In order to see that my proposal is properly suited for perceptualism, we need to examine more closely also the object or content of these experiences, though. In addition to making them intelligible as presentations, we must also show that the demands presented by them may qualify as instances of the relevant deontic (i.e. favoring) relation. It may not be obvious that what prescriptively affords a certain action also constitutes a corresponding concern-based normative reason. Furthermore, there is an issue of generality that needs addressing. As I noted in Sect. 2, normative reasons need not be furnished by the sensory environment. Since

\footnotetext{
31 An anonymous referee objected that it seems natural to enquire about reasons for impressions of prescriptive affordances. For example, in the case of Close Talker it seems natural to ask 'why do you feel a need to move away from you colleague?' I agree that this question can be construed as a request for reasons. However, in this case it does not refer to an experience of a prescriptive affordance. On the most natural reading, 'feel a need to $\phi$ ' does not express awareness of (perceiving or experiencing of) a deontic property. Rather, like 'war' in 'fight a war' or 'move' in 'make a move', in this context 'need to $\phi$ ' is a cognate accusative. As such, it qualifies the manner of feeling rather than ascribe an object to an experience. In this connection, cf. Ducasse (1952), Douglas (1998). The locution is thus best understood as ascribing an occurrent conative state, which might also be described by the locution 'feel in need to $\phi$ '. While this conative state does admit of reasons-we tend to feel this way in light of some aspect of our situation-, it is like any other response not a case of presentation. As far as I can see, this question can be appropriate if the person experiencing the colleague as to be backed away from also feels in need of backing away from her. But, given my above remarks on the phenomenology of non-deliberative action, I doubt that this has to be so.

32 Siegel (2014, p. 55) argues that experiences of solicitations need not be motivational. For example, you can hear music that is designed to dance as soliciting dancing without feeling any pull to dance. I agree, though I would maintain that when the solicitation is grounded in a concern of yours, the experience is motivational. Siegel's counter-examples are best conceived on the model of external directives. In the present example, the composer or producer of the tune intends you to dance along. But it fails to speak to your own motivational set.
} 
the experiences I have considered so far are exclusively of demands pertaining to objects we experience sensorily, there is a question as to whether the proposal can accommodate for the apprehension of normative reasons that are not provided by things available to our senses.

In the next section, I address the first of these issues. In the remainder, I then argue that experiences of prescriptive affordances form part of a broader class of presentations, which includes presentations of the favoring-character of reasons that are not sensorily accessible.

\section{Affordances and the force of normative reasons}

\subsection{Analogies between prescriptive affordances and concern-based normative reasons}

To show that prescriptive affordances may constitute exemplifications of the favoringrelation, I would first like to call attention to a number of similarities between both types of relational property.

(a) Dependence on concerns One notable parallel is that both concern-based normative reasons and prescriptive affordances are grounded by aspects of an agent's motivational set. Aspects of our surroundings prescriptively afford $\phi$ ing in virtue of their relevance to our concerns. Similarly, a concern-based reason to $\phi$ speaks in favor of $\phi$ ing in virtue of bearing on our desires, needs or interests.

It might be thought that, put in these general terms, the parallel obscures an important disanalogy. That is, one might doubt that both types of relational property depend on the same kinds of concerns. One way to spell out the worry is in terms of the aforementioned generality issue: it looks as though the concerns grounding prescriptive affordances are such that the sensory environment bears on their satisfaction, while no such constraint applies to the concerns grounding practical reasons. I address this issue in the final section. But there is another way of developing this worry. If we consult the literature on affordances, it seems there is no additional constraint on the kinds of cares that may generate prescriptive affordances. Setting aside the connection to the sensory environment, pretty much any desire, interest or need may ground prescriptive affordances. At the same time, it is controversial whether concerns in general may generate reasons for action. There are familiar examples, involving cruel, masochistic or bizarre desires (e.g. Quinn 1993), which can seem to restrict the set of concerns apt to ground practical reasons. Thus, if many prescriptive affordances depend on concerns that do not generate reasons, they cannot be concern-dependent reasons.

This is no problem for my proposal, though, since it does not require that all prescriptive affordances constitute exemplifications of the favoring-relation. My claim is that presentations of prescriptive affordances may provide access to the force of concern-based normative reasons. For this it is required that concernbased normative reasons depend on concerns that also generate prescriptive affordances. If, setting aside our sensory surroundings, there are no restrictions 
on the concerns that generate prescriptive affordances, this requirement is met. What matters is that the concerns that generate practical reasons are a subset of those that generate prescriptive affordances, not vice versa.

(b) Dependence on abilities and guidance Like Gibsonian affordances, prescriptive affordances are tied to an agent's abilities. For your colleague in Close Talker to prescriptively afford backing away, you must have the ability to perform this action. Similarly, a state of affairs constitutes a normative reason to $\phi$ only if you are able to $\phi$. This constraint is the reason-theoretic pendant of ought implies can (e.g. Streumer 2007; Vranas 2007). It is sometimes also implicitly adopted in defending the related, but distinct constraint that reasons must be able to guide us (e.g. Kolodny 2005; Parfit 2011, p. 51, among others). This view says that $x$ is a reason to $\phi$ only if you are able to $\phi$ in response to $x$.

Is there a guidance constraint on prescriptive affordances? While, to my knowledge, no such constraint has been explicitly formulated, the same core consideration that motivates this constraint in the case of normative reasons can be shown to apply to prescriptive affordances, too. According to a common idea, normative entities, that is, entities which in some way constrain or give directions on how to behave, must be able to make an actual difference to our behavior. That is, we must be able to act as they direct on account of their directions. This idea applies to prescriptive affordances no less than to normative reasons. The point of prescriptive affordances, much as the point of normative reasons, is to give directions on how to conduct.

(c) Hybrid ontological status A further commonality closely related to the first two similarities is that both prescriptive affordances and concern-based normative reasons are grounded partly by features of the agent and partly by features of her circumstances. The close talker prescriptively affords backing away not only in virtue of your concern to keep a comfortable distance and your ability to move backwards, but also in virtue of her behavior and her physical proximity. Similarly, that it is raining is a reason for you to take the umbrella both in virtue of your desire to stay dry and your ability to use umbrellas and in virtue of the effect of being hit by rain drops. Both relational properties might thus be described as a kind of ontological hybrid.

It is important to point out that this observation is compatible with their recognition as being objective in a substantial sense. In particular, both types of entity may provide standards of accuracy for presentations and beliefs (re)presenting them. One may be wrong about what one's surroundings prescriptively afford, just as one may be wrong about the concern-based normative reasons it provides. A lifelike plastic cake which is experienced as to be eaten does not actually speak to your taste. It lacks the kinds of properties in virtue of which it could satisfy your taste. Accordingly, there is a clear sense in which eating it is not actually called for and your experience is illusory. Conversely, where it has the relevant properties, it seems natural to say that it does demand eating. ${ }^{33}$ In this case, your experience is veridical. The same holds true of concern-based normative reasons.

\footnotetext{
33 This seems the right thing to say irrespective of whether you experience the demand. Modifying the case, you might e.g. first fail to have any experience of its prescriptive affordances and only come to realize in hindsight that, given that it is to your taste, the cake actually demanded eating.
} 
Whether or not something favors a certain action relative to your concerns is independent of whether or not you take it to favor this action.

(d) Strength Both prescriptive affordances and normative reasons may vary in strength. Moreover, the strength of a prescriptive affordance is determined in the same way as the strength of a concern-based normative reason.

Consider, first, the strength of the demand you sense in experiencing a prescriptive affordance. Plausibly, one influence on its strength is the strength of the concern from which it derives. The more you care about your peripersonal space, the stronger the experienced force of the solicitation. ${ }^{34}$ In addition, its strength seems to depend on the extent to which, from your perspective, giving into the affordance promotes the satisfaction of this concern. If you deemed this action useless (e.g. because you expected your interlocutor to immediately move forward and close the distance), backing away would very likely strike you as less pressing. Now, in accordance with my remarks about the objectivity of prescriptive affordances, we might here want to draw a distinction between experienced strength and actual strength. Intuitively, the stronger your concern to keep a distance, not only will you feel a stronger demand to back away, but, other things being equal, your colleague's proximity also actually demands this more strongly. In support of this, consider how you might assess the situation in hindsight after having failed, maybe out of false politeness, to respond accordingly. The more strongly your care about your peripersonal space, the more you would think of yourself as having failed to act appropriately. If we think of prescriptive affordances as accounting for the appropriateness of the actions they solicit, it seems natural to here appeal to the actual strength of the affordance as determined by the strength of your concern. Experienced and actual strength may also come apart, though. This may happen when the expected effectivity of your action deviates from the extent to which it actually promotes this concern. If backing away were of limited use to satisfy your concern, this would seem to decrease the extent to which this is objectively called for even if, to you, this action seems an effective means to take. In such a case, the experienced strength of the affordance will be different from its actual strength.

As it turns out, these two influences on the actual strength of prescriptive affordances - strength of the grounding concern and effectiveness of the action in promoting this concern - are standardly held to determine also the strength of concern-based normative reasons. For example, how strongly taking the umbrella is favored by the rain depends on how much you care about staying dry as well as by the extent to which that action is helpful in satisfying this concern. It is fair to note that that view is not universally accepted (Schroeder 2007, chapter 5.4). Yet it is clearly the mainstream position on the strength of concern-based reasons and well supported both by

\footnotetext{
34 Some might argue that what matters is not so much the actual strength of the concern, but its experienced strength. As far as I can see, nothing of substance hangs on this. As long as the reader agrees with my account of the actual (as opposed to experienced) strength of prescriptive affordances (see main text below), the intended parallel with the strength of concern-based normative reasons holds.
} 
pre-theoretical and theoretical considerations. ${ }^{35}$ I take this to warrant some confidence that the two types of relational property share a further important similarity.

If the various similarities I have noted are genuine, concern-based reasons and prescriptive affordances are analogous in several important respects. One might see this as the basis of an argument from analogy for the claim that the latter may constitute the normative force of the former. However, while these analogies will prove dialectically important, it seems to me that a stronger case for this claim can be made. Before I show this, however, I would like to supplement these remarks by acknowledging a putative disanalogy that might seem to tell against my proposal. This will at the same time bring to the fore a further consideration that will help establish this claim.

\subsection{A putative disanalogy}

Notwithstanding their common hybrid status, prescriptive affordances and concernbased normative reasons purportedly differ in that each relational property is exemplified by different kinds of entities. The favoring-relation is exemplified by states of affairs. In contrast, prescriptive affordances pertain to aspects of the sensory environment which are typically individual objects, such as ordinary material objects and people. ${ }^{36}$ As individual objects bearers of prescriptive affordances belong to a different ontological category than states of affairs. But if prescriptive affordances generally pertain to a different type of entity than the favoring-relation, this casts doubt on whether they are of the right ontological kind to constitute instances of this relation.

This worry is to some extent an artefact of certain degree of imprecision in characterizing prescriptive affordances. As suggested by my remarks in the foregoing subsection, an adequate characterization of the bearer of a prescriptive affordance always specifies certain properties. It is not your colleague simpliciter, but qua being too close, that prescriptively affords backing away. Likewise, in Cake and Beat, it is the cake and the music qua bearer of properties that make them conform to your taste which demand eating and tapping along to, respectively. In general, the property of prescriptively affording $\phi$ ing pertains to objects in virtue of exemplifying properties that relate to some concern. This makes bearers of prescriptive affordances quite similar to states of affairs.

Now, one might acknowledge that an object qua $F$ is very similar to the state of affairs that it is $F$ but maintain that both are nonetheless distinct sorts of entity (Lewis 2003). Although I here do not wish to take any stand on the metaphysics of qua-objects, I do not think that a metaphysical difference along these lines poses any threat to my claim. To appreciate this, it is helpful to note that for each object prescriptively affording $\phi$ ing, there is also a corresponding state of affairs with the

\footnotetext{
35 For defenses of the view against Schroeder's objections, cf. Evers (2014), Rieder (2016) and Fischer (2018, chapter 6.3).

36 As Siegel (2014) points out, situations may solicit action, too. For example, a particular traffic situation may solicit crossing the road. If situations are states of affairs (Kratzer 1989), in these cases the bearer of the affordance is the same type of entity as a normative reason. In discussing the present worry I shall focus on prescriptive affordances furnished by individual objects. But what I have to say applies to prescriptive affordances pertaining to situations, too, regardless of how they are conceived.
} 
same normative force. If the talker qua too close demands backing away, this is also true of her being too close. More generally, if an object $o$ qua $F$ demands $\phi$ ing, so does the corresponding state of affairs of $o$ 's being $F$. Moreover, it seems reasonable to think that here we have a single prescription which pertains both to $o$ qua $F$ as well as to the corresponding state of affairs. This is supported by the following thought: If you were to deliberate about how to respond to the close talker, you would clearly not count the demand associated with the talker qua too close to be an additional requirement over and above the demand associated with the corresponding state of affairs. Rather, in making up your mind, you would take there to be only one prescription which is an attributive property of both. This suggests that the demands constitutive of prescriptive affordances are of the right kind to constitute the force of concern-based normative reasons: these demands can be attributive properties not only of qua-objects, but also of states of affairs.

\subsection{Prescriptive affordances as exemplifications of the favoring-relation}

In order to devise a positive argument for the view that prescriptive affordances may constitute the force of a normative reason, I will exploit the insight that for each prescriptive affordance pertaining to an object there is a state of affairs with the same normative force. As I noted, it is controversial whether all prescriptive affordances are grounded on concerns that generate practical reasons. Thus, it does not follow that the corresponding state of affairs is always a concern-based normative reason. However, in those cases where a prescriptive affordance is grounded on a reasongenerating concern, it makes sense to suppose that it is. More specifically, in such a case the prescriptive affordance is identical to the normative force of a corresponding concern-based reason. Given the analogies I have highlighted, in this type of case, it is relevantly similar to the favoring-relation as exemplified by this reason. Both depend on the same concern, the same abilities as well as the same situational features. And the strength of each is proportionate to the strength of this concern and the degree to which the action promotes its satisfaction. This makes it compelling to suppose that the affordance that attaches both to the bearer of these features and to the corresponding state of affairs is an instance of the favoring-relation. Positing an exemplification of this relation in addition to the affordance seems superfluous. The simplest and most plausible way to think of this type of case is to assume that the force of the normative reason and the prescriptive affordance are one and the same thing.

We can further illustrate and support this line of thought with the help of the by now familiar examples. Note, first, that these examples confirm the claim that, given a suitable concern, the state of affairs corresponding to a prescriptive affordance is a normative reason. Inasmuch as you like the kind of cake that has just arrived at your neighbor's table, her dessert not only palpably demands trying. It also gives you reason to have some yourself. The cake being to your taste speaks in favor of your having a piece because, given that it has certain properties, eating it will satisfy your taste. This is supported by the observation that the state of affairs corresponding to the affordance can be cited in response to a request to justify your action. Thus, were your neighbor to remark 'I see you're going for some cake, too', it would be appropriate 
for you to respond: 'Sure, this is exactly the sort I like.' In doing so, you are indicating a normative reason for your order. Similarly, in the case of Close Talker, there is both a prescriptive affordance and a corresponding practical reason. Insofar as keeping distance matters to you her being too close is a reason to step away, which can be cited in justifying your action. (The same, I take it, is true mutatis mutandis of Beat.) Now, if in each of these cases, the state of affairs corresponding to the affordance also favors the demanded action, the analogies between the affordance and the force of the reason provide strong abductive grounds to identify the two. We can explain this observation in the simplest and most plausible way by supposing that the respective affordance is identical to the normative force of this state of affairs qua concern-based reason.

Supposing this argument is sound, the crucial upshot is that experiences of prescriptive affordances not only qualify as presentations, but may in fact constitute presentations of the favoring-relation as exemplified by concern-based normative reasons. Given the appropriate grounding concerns, the prescriptive affordance presented is an instance of this relation. Accordingly, when these experiences are veridical, they may provide access to a concern-based normative reason. Experiences of prescriptive affordances thus look like a good candidate for the perceptualist's target phenomenon.

\section{Substantiating the proposal}

To address the generality issue, let me finally outline an account of the nature of experiences of prescriptive affordances. Reasons of space forbid that I offer more than a sketch. But if my account is on the right track, it provides some warrant for thinking that they may provide access also to the force of reasons furnished by things to which we have no sensory access. Moreover, what I say should provide some additional ground to recognize them as a non-mysterious aspect of our psychology. In devising this account, I draw on a conception of the apprehension of concerndependent evaluative properties, which, building on work by Roberts (2003, 2013), I have developed elsewhere (Müller 2019, chapter 5).

As I would like to propose, experiences of prescriptive affordances are a type of aspectual presentation. That is to say that they are structurally on a par with paradigm cases of aspectual perception, such as seeing someone's face as similar to another's face or seeing the duck-rabbit as a duck. To confer some plausibility on this claim, let me begin by specifying some central structural features of aspectual perception.

In aspectual perception a certain feature of some perceived object is presented as a result of apprehending or construing this object in specific terms. In seeing a face as similar to another, one has an impression of similarity by virtue of construing the perceived face in terms of the other face, which is represented by a mental image or visually perceived, too. The content of this experience is determined by the terms in which the perceived object is apprehended. In the present example, the second face provides a standard of congruence in terms of which one construes the first one. That is, the terms in which the latter is construed are those of (dis)similarity or (in)congruence with respect to the former.

It is important here to distinguish the act of construing something in certain terms from the formation of judgment or belief. This act is not an inference or assent to a prior 
impression or thought. In construing something in certain terms, you are saddled with a certain content: the face strikes you as being some way in virtue of being construed by you in this way. Moreover, as I noted in Sect. 3.2, the act of construing is here to be distinguished from the presentational state to which it gives rise (the corresponding construal).

In line with Roberts (2003, 2013), I take this basic account of ordinary seeing-as to be applicable to a considerably large class of experiences. There are many presentations which we enjoy by virtue of construing something in certain terms, including nonsensory ones. Consider the example from Sect. 3.1 of being struck by the invalidity of an inference. Here, we have an impression of logical impropriety. More specifically, it is a non-sensory presentation of impropriety relative to a certain conception of validity. Taking aspectual perception as our model, we can think of this impression as the upshot of construing the inference in certain terms. The terms are, again, those of (in)congruence. That is, your conception of validity provides a standard of congruence in terms of which the inference is construed. Thus conceived, the case exhibits the core structure of seeing-as. It is, at a certain level of abstraction, the same kind of psychological phenomenon as seeing a face as alike another.

It seems that presentations of prescriptive affordances naturally lend themselves to being treated accordingly. In the cases I have considered thus far, the respective presentation is the result of apprehending a sensorily experienced object in certain terms. What is specific to this form of aspectual presentation is that the terms are supplied by the agent's concerns. That is, one enjoys an impression as of some perceived object $o$ demanding $\phi$ ing by virtue of construing $o$ in terms of a certain desire, interest or need. Here, too, the construal is one of (in)congruence. Remember that, as I elaborated on Close Talker, your experience involves a certain tension. This felt tension is an experienced incongruence with your concern to keep a comfortable distance. More precisely, the relevant standard of comparison is provided by the state of affairs specified by the content of this concern. In construing your colleague in terms of this concern her behavior and relative location appear to you as incongruent with maintaining a comfortable distance. By contrast, in Cake and Beat, you enjoy an impression of congruence in construing things in terms of your tastes.

We can shed some more light on the directive aspect of these presentations by looking more closely at the role of concerns as standards of congruence. As I conceive of this role, concerns provide such a standard in a substantial, normative sense. The content of a concern specifies something whose pursuit or realization has import for the agent. Accordingly, when construing something in terms of a concern, the latter provides a standard of congruence whose achievement matters. This is not the case when the terms of construal are provided by purely cognitive states, as in being struck by a likeness between two faces or the invalidity of an inference. In these cases, the act of construing is informed by a standard of congruence, too, but there is no stake in meeting this standard. This difference bears on the resulting presentation in the following way. When the terms of the construal are provided by a concern, the experience is not only of the object's (in)congruence with its content but also 
of means to take to bring about or maintain its satisfaction. ${ }^{37}$ In Close Talker, the action of backing away is required by way of keeping a comfortable distance and thus recreating the state of affairs that satisfies your concern. Since it matters to you that this state of affairs obtains, the impression you enjoy in construing your interlocutor in terms of this concern includes a corresponding solicitation. The action is experienced as demanded because of the way you are personally invested into protecting your peripersonal space in having this concern. That this space is at stake informs the impression of your colleague so as for her to be presented as favoring a way to protect it.

A lot more could, and should, be said about the act of construing something in terms of concerns and how this determines the content of the resulting experience. While my remarks here have to remain tentative, they, however, provide the contours for an account that assimilates experiences of prescriptive affordances to a familiar sort of non-normative presentation. This is a substantive account on which presentations of prescriptive affordances form part of a larger class of experiences that are unified by their character as construals.

Since construals need not involve any sensory content, the proposed view makes room also for presentations of prescriptive affordances that pertain to entities we cannot sensorily access. Developing my example from Sect. 3.1, imagine that you have performed the inference yourself and that your care about sound reasoning. Given my take on the previous examples, this plausibly influences the way the inference strikes you. In being struck by its impropriety you also experience a tension with this concern and a corresponding demand to try and rectify things. Treating the case as a concerndependent construal, we can say that the inference is construed by you both in terms of your conception of validity and in terms of your concern for proper reasoning. Accordingly, the impression you receive by construing the inference in these terms includes a demand to make it conform with this concern. In thus construing it, you have a non-sensory impression of a concern-based reason to make the inference valid.

Considering this case, it seems that treating experiences of prescriptive affordances as aspectual presentations provides resources to deal with the generality worry. If we think of experiences of prescriptive affordances as aspectual perceptions along the lines I have proposed, they come in suitably many forms as to provide access also to concern-based reasons beyond those provided by our sensory surroundings. This further supports my claim that they make a suitable candidate for the perceptualist's target phenomenon. Moreover, this claim is corroborated not least by the general structural similarities with ordinary seeing-as highlighted by this account. That is, if my take proves accurate and presentations of prescriptive affordances and ordinary cases of aspect perception are, at a more abstract level, the same sort of mental state, this

\footnotetext{
37 This explication of the directive aspect of concern-based construals has some echoes with Schroeder's (2007, chapter 8.4) and Milona and Schroeder's (2019) view that desires involve perceptions of reasons to take actions suitable to their fulfillment. These authors do not spell out their view in terms of concernbased construals, though, and do not characterize the associated perceptions as presentations of prescriptive affordances. Moreover, their view is concerned specifically with desires rather than concerns in general. Also, in contrast to them, I do not contend that the relevant perceptions are involved in or part of conative states. My claim is only that they are the upshot of construing one's situation in terms of a certain concern.
} 
should also help assuage any remaining worries to the effect that they are themselves too obscure to deserve serious consideration.

\section{Conclusion}

I argued in favor of a perceptualist view of the apprehension of normative reasons, focusing on concern-based practical reasons. Assessing Dancy's case for perceptualism, I argued that it is crucial to distinguish between presentations and responses in order to avoid misidentifying which actual psychological phenomena are apt to present normative reasons. I then developed an alternative view on which access to concernbased reasons is provided by experiences of prescriptive affordances. As I tentatively argued, these experiences are aspectual presentations which are structurally analogous to ordinary cases of seeing-as.

Acknowledgements I am very grateful to both anonymous referees for carefully reading the paper and for their insightful remarks and suggestions. Moreover, I would like to thank Sabine Döring and the participants of her research colloquium at the University of Tübingen for very valuable feedback on earlier versions of this material. I am also grateful to Peter Königs for his written comments, as well as Hichem Naar for extensive discussion.

Funding Open Access funding enabled and organized by Projekt DEAL.

Open Access This article is licensed under a Creative Commons Attribution 4.0 International License, which permits use, sharing, adaptation, distribution and reproduction in any medium or format, as long as you give appropriate credit to the original author(s) and the source, provide a link to the Creative Commons licence, and indicate if changes were made. The images or other third party material in this article are included in the article's Creative Commons licence, unless indicated otherwise in a credit line to the material. If material is not included in the article's Creative Commons licence and your intended use is not permitted by statutory regulation or exceeds the permitted use, you will need to obtain permission directly from the copyright holder. To view a copy of this licence, visit http://creativecommons.org/licenses/by/4.0/.

\section{References}

Audi, R. (2014). Moral perception. Princeton: Princeton University Press.

Bedke, M. (2009). The iffiest oughts: A guise of reasons account of end-given conditionals. Ethics, 119(4), 672-698.

Bedke, M. (2010). Might all normativity be queer? Australasian Journal of Philosophy, 88(1), 41-58.

Bengson, J. (2015). The intellectual given. Mind, 124(495), 707-760.

Bittner, R. (2001). Doing things for reasons. Oxford: Oxford University Press.

Brentano, F. (1995). Psychology from an empirical standpoint. (A. C. Rancurello, D. B. Terrell \& L. L. McAlister Trans.). London: Routledge.

Brownstein, M., \& Madva, A. (2012). The normativity of automaticity. Mind and Language, 27(4), 410-434.

Chappell, T. (2008). Moral perception. Philosophy, 83(4), 421-437.

Chudnoff, E. (2013). Intuition. Oxford: Oxford University Press.

Church, J. (2013). Possibilities of perception. Oxford: Oxford University Press.

Cowan, R. (2015). Perceptual intuitionism. Philosophy and Phenomenological Research, 90(1), 164-193.

Dancy, J. (2014). Intuition and emotion. Ethics, 124(4), 787-812.

Deonna, J., \& Teroni, F. (2012). The emotions. London: Routledge.

Dietz, C. (2018). Reasons and factive emotions. Philosophical Studies, 175(7), 1681-1691.

Dokic, J. (2010). Affordances and the sense of joint agency. In B. Michela (Ed.), Neuropsychology and the sense of agency (pp. 23-43). Milano: Springer. 
Douglas, G. (1998). Why pains are not mental objects. Philosophical Studies, 91(2), 127-148.

Dreyfus, H., \& Kelly, S. (2007). Heterophenomenology: Heavy-handed Sleight-of-Hand. Phenomenology and the Cognitive Sciences, 6(1-2), 45-55.

Ducasse, C. J. (1952). Moore's refutation of idealism. In P. A. Schilp (Ed.), The Philosophy of G.E. Moore (pp. 225-251). New York: Tudor.

Evers, D. (2014). In defence of proportionalism. European Journal of Philosophy, 22(2), 313-320.

Fischer, S. (2018). The origin of oughtness. Berlin: De Gruyter.

Gendler, T. S. (2008). Alief and belief. Journal of Philosophy, 105(10), 634-663.

Gibson, J. (1979). An ecological approach to visual perception. Boston: Houghton Mifflin.

Goldie, P. (2004). Emotion, feeling and knowledge of the world. In R. Solomon (Ed.), Thinking about feeling (pp. 91-106). Oxford: Oxford University Press.

Helm, B. (2001).Emotional reason. Cambridge: Cambridge University Press.

Kauppinen, A. (2013). A humean theory of moral intuition. Canadian Journal of Philosophy, 43(3), $360-381$.

Kauppinen, A. (2018). The world according to suffering. In D. Bain, M. Brady, \& J. Corns (Eds.), Philosophy of suffering (pp. 19-36). Oxford: Routledge.

Kelly, S. (2005). Seeing things in Merleau-Ponty. In T. Carman (Ed.), The Cambridge companion to MerleauPonty (pp. 74-110). Cambridge: Cambridge University Press.

Koffka, K. (1935). Principles of gestalt psychology. New York: Harcourt Brace.

Kolodny, N. (2005). Why be rational? Mind, 114, 509-563.

Kratzer, A. (1989). An investigation of the lumps of thought. Linguistics and Philosophy, 12(5), 607-653.

Kriegel, U. (2012). Personal-level representation. In S. Miguens \& G. Preyer (Eds.), Consciousness and subjectivity (pp. 109-146). Frankfurt am Main: Ontos.

Kriegel, U. (2018). Brentano's philosophical system. Oxford: Oxford University Press.

Lewis, D. (2003). Things qua Truthmakers. In H. Lillehammer \& G. Rodriguez-Pereyra (Eds.), Real metaphysics (pp. 25-42). London: Routledge.

Lowe, J. (2008). Personal agency. Oxford: Oxford University Press.

Macarthur, D. (2015). Review of possibilities of perception by Jennifer Church. Australasian Journal of Philosophy, 93(1), 178-182.

Mackie, J. L. (1977). Ethics. Harmondsworth: Penguin.

Mantel, S. (2015). Worldly reasons: An ontological inquiry into motivation considerations and normative reason. Pacific Philosophical Quarterly, 98(S1), 5-28.

Meinong, A. (1972). On emotional presentation. (M.-L. Schubert Kalsi., Trans.) Evanston: Northwestern University Press.

Mendelovici, A. (2018). The phenomenal basis of intentionality. New York: Oxford University Press.

Milona, M. (2017). Intellect vs. affect: Finding leverage in an old debate. Philosophical Studies, 174(9), 2251-2276.

Milona, M., \& Naar, H. (2020). Sentimental perceptualism and the challenge from cognitive bases. Philosophical Studies, 177(10), 3071-3096.

Milona, M., \& Schroeder, M. (2019). Desiring under the proper guise. In R. Schafer-Landau (Ed.), Oxford studies in metaethics (Vol. 14, pp. 121-143). Oxford: Oxford University Press.

Mitchell, J. (2019). Pre-emotional awareness and the content-priority view. The Philosophical Quarterly, 69(277), 771-794.

Müller, J. M. (2017). How (Not) to think of emotions as evaluative attitudes. Dialectica, 71(2), 281-308.

Müller, J. M. (2019). The world-directedness of emotional feeling. Cham: Palgrave Macmillan.

Mulligan, K. (2007). Intentionality, knowledge and formal objects. Disputatio, 23(2), 205-228.

Noë, A. (2003). Causation and perception: The puzzle unraveled. Analysis, 63(2), 93-100.

Norrick, N. R. (1978). Factive adjectives and the theory of factivity. Tübingen: Niemeyer.

Oddie, G. (2005). Value, reality and desire. New York: Oxford University Press.

Parfit, D. (2011). On what matters (Vol. 2). Oxford: Oxford University Press.

Peacocke, C. (2004). The realm of reason. New York: Oxford University Press.

Poellner, P. (2016). Phenomenology and the perceptual model of emotion. Proceedings of the Aristotelian Society, 116(3), 261-288.

Quinn, W. (1993). Putting rationality in its place. Morality and action (pp. 228-255). Cambridge: Cambridge University Press.

Rieder, T. (2016). Why I'm still a proportionalist. Philosophical Studies, 173(1), 251-270. 
Rietveld, E. (2008). Situated normativity: The normative aspect of embodied cognition in unreflective action. Mind, 117, 973-1001.

Rietveld, E., \& Kiverstein, J. (2014). A rich landscape of affordances. Ecological Psychology, 26, 325-352.

Roberts, R. (2003). Emotions. Cambridge: Cambridge University Press.

Roberts, R. (2013). Emotions in the moral life. Cambridge: Cambridge University Press.

Scanlon, T. (1998). What we owe to each other. Cambridge: Harvard University Press.

Scanlon, T. (2014). Being realistic about reasons. Oxford: Oxford University Press.

Scheler, M. (1973). Formalism in Ethics and Non-formal Ethics of Values. (M. S. Frings \& R. L. Funk, Trans.). Evanston: Northwestern University Press.

Schellenberg, S. (2013). Experience and evidence. Mind, 122(487), 699-747.

Schroeder, M. (2007). Slaves of the passions. Oxford: Oxford University Press.

Searle, J. (1983). Intentionality. Cambridge: Cambridge University Press.

Siegel, S. (2014). Affordances and the contents of perception. In B. Brogaard (Ed.), Does perception have content? (pp. 39-76). Oxford: Oxford University Press.

Shafer-Landau, R. (2003).Moral realism: a defence. New York: Oxford University Press.

Shepherd, J. (2016). Conscious action/zombie action. Noûs, 50(2), 419-444.

Streumer, B. (2007). Reasons and impossibility. Philosophical Studies, 136, 354-381.

Tappolet, C. (2016). Emotions, value and agency. Oxford: Oxford University Press.

Textor, M. (2007). Seeing something and believing in it. In M. M. McCabe \& M. Textor (Eds.), Perspectives on perception (pp. 65-87). Frankfurt am Main: Ontos.

von Hildebrand, D. (1969). Die Idee der sittlichen Handlung (Special ed.). Darmstadt: Wissenschaftliche Buchgesellschaft.

Vranas, P. (2007). I ought, therefore i can. Philosophical Studies, 136, 167-216.

Publisher's Note Springer Nature remains neutral with regard to jurisdictional claims in published maps and institutional affiliations. 